\title{
APONTAMENTOS PARA UMA LÍRICA MÍNIMA
}

\author{
Phabulo Mendes de Sousa ${ }^{1}$
}

RESUMO: Este artigo pretende mostrar a existência de uma "lírica mínima" na obra da poetisa contemporânea portuguesa Adília Lopes, valendo-se de considerações e apontamentos críticos feitos pela própria poetisa para identificar essa forma mínima de poesia.

PALAVRAS-CHAVE: poesia; contemporaneidade; ironia; lírica mínima.

\section{NOTES TO A MINIMAL LYRIC}

ABSTRACT: This article aims to show the existence of a "lyrical minimal" in the work of contemporary Portuguese poet Adília Lopes. For this, there are considerations and critical notes made by the poet to identify this minimal form of poetry.

KEYWORDS: poetry; contemporaneity; irony; minimal lyric poetry.

\footnotetext{
${ }^{1}$ Mestrando em Literatura Portuguesa - FFLCH/ USP.
} 
Adília Lopes, pseudônimo de Maria José da Silva Viana Fidalgo de Oliveira, poetisa contemporânea portuguesa, teve sua entrada no mundo literário em 1985 com a publicação de Um jogo bastante perigoso. Nesse livro estão presentes alguns traços estilísticos recorrentes em sua produção poética, como a mistura de gêneros, a ironia e o humor. A precisão de seus versos, somada à latente ironia presente em boa parte de seus poemas, garante à sua poesia um lugar particular no cenário poético da atualidade. Ainda que alvo de muitas críticas, sua obra, traduzida para alguns idiomas, como o francês e o italiano, é acompanhada de perto por um público fiel, e passa a frequentar cada vez mais os meios acadêmicos. Segundo Rosa Maria Martelo Adília Lopes, com o passar dos anos "foi sendo objecto de uma atenção crescente, atenção essa que nem sempre exclui alguma perplexidade perante a sua escrita." (MARTELO, 2010, p. 223). Parte dessa dificuldade e perplexidade, segundo Martelo, deve-se ao fato de a poetisa mesclar em sua poesia universos e discursos distintos. Assim, em um mesmo poema podemos encontrar tanto referências da alta literatura, como elementos da cultura de massas.

Essa verdadeira mistura serve para adornar os mais diferentes temas abordados em sua obra. Levando em consideração essa singularidade de sua escrita, o objetivo deste artigo é apontar a existência de uma "lírica mínima" na poética de Adília Lopes. Para isso, os poemas que serviram de exemplo para mostrar essa "lírica mínima" serão lidos e analisados, principalmente, à luz de apontamentos críticos feitos pela poetisa sobre sua obra.

Percorrendo os seus vários livros de poesia, encontramos alguns poemas que abordam e problematizam o ato da escrita e o papel do escritor. Em seu livro $A$ mulher-adias, Adília Lopes apresenta por meio de um "manifesto" a função que o autor precisa ter, assim como as ações necessárias que deve tomar em relação à literatura.

\section{MANIFESTO}

para a Lúcia Sigalho

O autor (o actor)

tem de se levantar

e de se pôr

como o Sol

o autor tem

de se expor

o autor tem

de pôr ovos 
de oiro (LOPES, 2009, p. 476) ${ }^{2}$

Salta aos olhos do leitor, à primeira vista, a concisão formal do poema. Seus versos, feitos com poucas palavras, contam também com o aproveitamento e a aproximação delas. Dessa forma, podemos identificar a aproximação fonética e semântica dos termos "autor" e "actor", no primeiro verso, assim como o uso distinto do verbo "pôr" no terceiro e no oitavo verso, somado à sua derivação no sexto verso (expor). Essas aproximações, além de contribuir para o ritmo e sonoridade do poema, ocasionam o tom aparentemente "descontraído" e bem humorado.

De acordo com Adília Lopes, o autor, visto também como um ator, precisa desenvolver certas ações, entre elas: percorrer, assim como o Sol, um determinado percurso (levantar e se pôr); e, durante a exposição que fizer neste percurso, ele precisa pôr (através de sua obra) "ovos de oiro".

Essa forma de escrever poesia, procurando aproveitar as palavras e extrair o máximo de significados valendo-se apenas do essencial, configura uma importante marca de sua poética. A última ação que o autor precisa fazer, de acordo com o manifesto, potencializa o tom humorístico do poema. Extraída do universo dos contos infantis, a imagem dos "ovos de oiro" gera humor, pois delimita o resultado do trabalho do autor, isto é, além da trajetória e da exposição que deverá fazer constantemente, o autor precisa certificar-se de que os "ovos" por ele postos sejam tão importantes e significativos como os preciosos ovos de ouro.

Esse modo de construir poesia aparece "teorizado" por Adília Lopes no livro citado anteriormente, publicado em 2002. Em uma nota introdutória, ela aponta uma modificação ocorrida em sua poesia. Segundo ela, seus poemas, no decorrer da década de 1990, tornaram-se "mais secos, mais pobres" e, ao mesmo tempo, "mais exuberantes, luxuriantes e corajosos" (LOPES, 2009, 445).

O aspecto "pobre" citado pela poetisa deve-se, sobretudo, à concisão de seus versos. Se em seus primeiros livros encontramos poemas com versos mais longos formados de seis ou mais palavras -, com a mudança formal, explicitada acima, houve um "enxugamento" deles. Muitos, após essa modificação, são feitos com apenas três ou quatro palavras. O poema Manifesto ilustra coerentemente essa concisão.

\footnotetext{
${ }^{2}$ A maioria dos poemas que serão analisados neste artigo foi retirada da última reunião dos livros de Adília Lopes. Lopes, Adília. Dobra. Lisboa: Assírio Alvim, 2009.
} 
Logo, os poemas, "pela disposição na página e pela sua feitura" podem ser vistos como "uma trança ou uma tripa" (LOPES, 2009, 445), ou seja, pelo desenho que vemos na folha de papel, eles são mais verticalizados. Essa característica formal explicita a imagem do poema como uma "trança" ou uma "tripa".

Além dessa modificação no modo de compor, a poetisa acrescenta mais um dado que corrobora o aspecto de "pobreza" de seus poemas. Segundo ela, para o ato da escrita, assim como pregava S. Francisco de Assis, é necessário pouco, e desse pouco, basta apenas o muito pouco. Este pouco almejado por Adília, espelhando-se nos preceitos defendidos pelo santo cristão, pode ser verificado em muitos poemas. Dentre eles:

\section{A solidão \\ engendra \\ monstros}

A hora
do jantar
é a pior
hora (LOPES, 2009, p. 593)

Em relação à forma, o poema acima parece comprovar a imagem usada pela poetisa. Vendo-o na página, percebemos claramente a alteração formal indicada por Adília. Formado de poucas palavras (o maior verso possui três palavras), ele se assemelha imageticamente a uma pequena "tripa", graças ao formato verticalizado. Quanto ao tema, Adília tece, através de uma estrutura simples e sucinta, uma breve consideração sobre a solidão.

Esse poema parece apontar os malefícios causados pela solidão. A primeira estrofe marca de modo direto e sucinto um aspecto bastante recorrente da solidão, isto é, a sua capacidade de engendrar "monstros". Em outras palavras, a solidão pode originar pensamentos negativos, responsáveis por gerar preocupação e mesmo desorientação nos homens. Dessa maneira, somos levados, muitas vezes, a criar complicações, as quais, por sua vez, produzem momentos difíceis e desagradáveis.

A segunda estrofe parece restringir e especificar o conteúdo da primeira. De acordo com ela, a hora do jantar é a pior hora para enfrentar esse sentimento. A partir dessa especificação temporal, podemos supor que em outros momentos a solidão também pode criar "monstros". Contudo, durante o jantar isso parece se intensificar - a repetição da palavra "hora", que abre e fecha a estrofe, parece corroborar a ideia defendida no poema. 
Apesar das modificações de hábitos e costumes, que acompanham as transformações sociais principalmente nos dias atuais, sabemos que a hora do jantar parece ser um dos momentos mais adequados para as pessoas se reunirem. Se essa ação é compartilhada por muitos, pela forma como aparece no poema, a hora do jantar apenas potencializa um estado de solidão. Se a solidão pode existir também em outros horários, durante o jantar parece não haver meios de escapar-lhe, já que é preciso lidar cara a cara com os "monstros" gerados por ela.

Ao traçar estas poucas palavras, Adília aborda um tema recorrente nos dias atuais. Mesmo convivendo em um mundo interligado e conectado, graças aos avanços tecnológicos, experimentamos, cada vez mais, momentos de solidão. Ainda que cercados de pessoas, nutrimos, muitas vezes, a sensação de estar sozinhos. Às vezes, a única companhia com que contamos parece ser, paradoxalmente, a da solidão.

Em linhas gerais, esse poema parece exemplificar a afirmação de Adília, segundo a qual seus poemas tornaram-se, com o passar dos anos, mais "secos", mas também passaram a ser mais "exuberantes, luxuriantes, corajosos". O aspecto exuberante reside justamente no fato de questionar e abordar temas, valendo-se apenas de poucas palavras. Para isso, a escolha de uma palavra é significativa e importante para a feitura do poema, uma vez que a riqueza "luxuriante" é encontrada não no excesso, mas no pouco.

Além dessas considerações, podemos identificar, nesse poema, uma aproximação entre a poesia e a prosa. A poesia de Adília Lopes é marcadamente prosaica. Há em seus versos um acentuado teor prosaico. Se alterarmos o aspecto visual do poema anterior, leríamos: "A solidão engendra monstros / a hora do jantar é a pior hora". Essa simples conversão revela mais claramente o conteúdo prosaico do poema. A presença dessa importante característica estilística aparece traduzida poeticamente:

Quanto mais prosaico mais poético

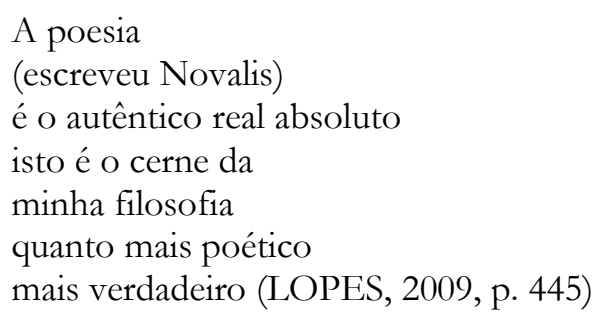

Sucintamente, Adília Lopes confirma a utilização do prosaico em sua poesia. Parafraseando a primeira estrofe do poema, quanto mais prosaico um poema, mais poético 
ele será. Dessa forma, o cerne de sua filosofia se baseia na concepção defendida pelo escritor romântico alemão Novalis, para quem a poesia deve ser vista como o "autêntico real absoluto".

A partir dessa indicação, podemos enxergar melhor a atenção que a poetisa dá ao cotidiano. Em muitos poemas, o que lemos são pequenas descrições:

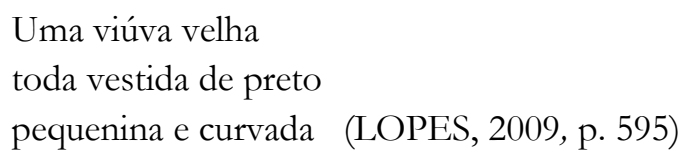

Esse "singelo" poema pode ser visto como um conciso retrato visual cujo objetivo é capturar, na curta estrofe, uma imagem precisa. A precisão dos detalhes - a vestimenta preta da pequena velha encurvada, que possivelmente está a andar pelas ruas -, registrada pela lente de Adília Lopes, transpõe para o campo poético uma simples e passageira cena cotidiana.

$\mathrm{O}$ ato de fixar poeticamente momentos ou ações simples que configuram o cotidiano reaparece constantemente em sua poesia. Com isso, uma simples ação ou um gesto rotineiro podem ser transpostos em versos:

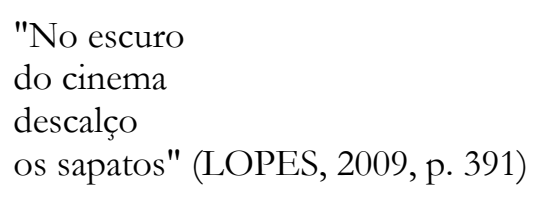

Em outro poema nos deparamos com o "simples" exercício do olhar:

"A porta verde da casa em frente" (LOPES, 2010, p. 19)

Podemos ler essas descrições e esses registros imagéticos como curtas cenas, nas quais apenas o elemento principal é emoldurado no texto. O efeito visual "exuberante" é o de uma câmera fotográfica que armazena de modo pontual somente os signos mais relevantes para a construção da imagem: seja o ato de descalçar os sapatos no escuro do cinema ou a cor da porta que desperta atenção. Adília procura, por meio desses pequenos fragmentos poéticos, uma reconfiguração do olhar. O leitor é convidado a ver com mais atenção uma ação ou uma imagem. Dessa forma, uma "cena" banal e repetida é adornada de contornos líricos.

Como um bom fotógrafo que capta o momento preciso do campo visual que pretende mostrar na imagem, esses pequenos quadros poéticos do cotidiano parecem dar ao ambiente prosaico e banal do dia a dia uma nova coloração. Assim, Adília Lopes faz 
com que seu leitor, diante dessas "fotografias verbais" veja o lirismo extraído apenas do essencial.

Voltando à "conceituação teórica" dada pela própria poetisa, encontramos nesses curtos registros poéticos um lirismo dotado de exuberância, a qual, por sua vez, resulta do "pouco" alcançado pela poesia, como também revela a concepção "corajosa" de seus poemas. É necessário, para que isso aconteça, um extraordinário poder de concisão. Tudo aqui é reduzido ao essencial. Mais uma vez, podemos verificar como o parâmetro de conduta religioso defendido por S. Francisco de Assis, é assimilado, esteticamente, pela poesia.

Como afirmado anteriormente, uma "faceta" literária bastante utilizada por Adília Lopes está no fato de combinar e aproveitar palavras, procurando extrair novos termos e outros sentidos. Essa característica contribui significativamente para a sua concisão poética, e consequentemente, para sua lírica mínima. Em muitos poemas, a raiz de um termo reaparece em outra palavra, ocasionando um preciso jogo linguístico. O poema a seguir é um bom exemplo.

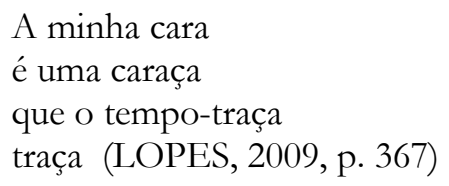

Assim como em outros poemas, o máximo é obtido aqui apenas com o pouco. Nesse poema, o aspecto "seco" guarda uma "corajosa" riqueza. Adília Lopes problematiza, com humor, dois importantes temas literários, a saber, o questionamento com a identidade do sujeito e a passagem do tempo. Esses questionamentos em si, tendo em mente sua complexidade, podem servir (e serviram) de matéria para longos poemas e extensas descrições e narrações. Já Adília, valendo-se de sua concisa fábrica poética, utiliza, inicialmente, apenas a aproximação fonética de algumas palavras para alcançar seu objetivo.

O questionamento da identidade do sujeito aparece nos dois primeiros versos: "a minha cara / é uma caraça". Essa simples afirmação para um leitor desatento pode soar ingênua. Contudo, ela atualiza, contemporaneamente, o debate existente em torno dos variados questionamentos sobre a crise do sujeito. O termo "caraça" serve para designar uma máscara geralmente de papelão. Dessa forma, ao afirmar objetivamente que sua "cara" é uma "caraça" - valendo-se da aproximação sonora e semântica desses termos - a poetisa aborda, com humor, a questão da identidade, a qual, no seu caso, parece bastante peculiar. 
Em se tratando de Adília Lopes, é irônica tal afirmação, pois quando diz ser seu rosto uma máscara, ela parece desnudar seu próprio jogo poético. Sabemos que Adília Lopes é um pseudônimo. Logo, afirmar que sua cara é uma máscara parece confirmar, por um lado, a existência da pessoa física que está por trás da "caraça" literária, mas também serve, por outro, para corroborar o embaralhamento que ela mesma alimenta em torno da figura de Maria José da Silva Viana Fidalgo de Oliveira (ser real?) e de Adília Lopes (caraça literária?) ${ }^{3}$.

Se essa "confusão" literária aparece nos dois primeiros versos, há, nos dois últimos, outro tema. Neles parece confirmada a inflexibilidade do tempo em tudo destruir e corroer. A maneira leve e bem humorada colocada por Adília parece tornar menos grave este assunto tão debatido no campo literário. Para isso, a poetisa usa a mesma palavra - "traça" de modo distinto. No terceiro verso ela aparece como segundo elemento do substantivo composto ("tempo-traça") e, no último, como a ação promovida pelo verbo traçar. Contudo, tanto em um como no outro o sentido é equivalente e complementar. Se separarmos a palavra "traça" do substantivo "tempo", teremos apenas o substantivo que alude diretamente ao inseto que corrói, com o passar do tempo, alguns objetos. As traças são responsáveis por provocar grandes desgastes em materiais como tecidos, tapetes, móveis etc. Vendo-o como adjetivo, ele torna ainda mais intensa a função que o tempo, que também pode ser visto como uma traça, imprime indistintamente na vida dos seres. A escolha do verbo "traçar", levando em consideração os versos anteriores, gera humor, ao mesmo tempo que marca, como uma flecha que atinge com precisão seu alvo, a função exercida pelo tempo. Assim, tanto o rosto quanto o artifício que podemos usar sobre ele (caraça) não passarão incólumes pelo tempo. Mesmo que uma máscara possa ser usada como utensílio para ocultar uma identidade, quando colocada diante do "tempo-traça" seus efeitos parecem não surtir efeito, uma vez que o implacável tempo é capaz de apagar traços muito resistentes.

Por meio desse jogo conciso, Adília Lopes aborda variados assuntos. Um exemplo bastante significativo presente em sua obra consiste na releitura feita dos contos infantis.

\footnotetext{
${ }^{3}$ É interessante notar que essa indagação (que também poderia ser uma forma de provocação) reaparece em muitos poemas. Ao abrir o livro Versos Verdes (antes publicado como Florbela Espanca espanca, 1999) Lê-se: "Este livro / foi escrito / por mim". Esse pequeno "apontamento", que abre seu livro, alimenta a discussão em torno de sua cara / caraça.
} 
Ela ora apresenta versões de histórias infantis, ora reescreve outras conhecidas, retirando delas todo o véu idealizado e atualizando-as com uma latente dose de ironia e maldade ${ }^{4}$.

No poema abaixo reconhecemos elementos próprios das histórias infantis. Valendo-se da imagem do poema como uma trança, Adília Lopes apresenta uma versão sucinta de um possível conto de fadas.

Era uma vez
uma donzela
que achou
uma mão
decepada
Pelo caminho
achou
um pastor
cheio de dor
porque um malfeitor
lhe tinha cortado
uma mão
para lhe roubar
um anel
A donzela
pregou a mão
ao braço
do pastor
E a dor
do pastor
ainda foi
maior (LOPES, 2009, p. 307)

Há alguns indícios no poema que remetem diretamente ao universo dos contos de fadas. O primeiro deles pode ser verificado no início do poema. Quando lemos o primeiro verso - "Era uma vez" -, somos remetidos ao mundo fantasioso dessas histórias. Pensando na tradição deste gênero literário, essa simples e "mágica" frase parece firmar um contrato com a imaginação, uma vez que serve para sinalizar o início dos contos infantis. Aliada a esse indício verbal, há também a presença de personagens que reitera o ambiente singular dos contos infantis, como a donzela, o pastor e o malfeitor.

Contudo, ao se apropriar desses elementos, Adília Lopes propõe uma cruel releitura. Esse poema, dividido em quatro partes - delimitadas pela letra maiúscula presente nos versos 1, 6, 15, 19 -, narra poeticamente a "aventura" destituída de lirismo de uma donzela que encontra pelo caminho uma mão decepada. Em seguida, encontra um pastor

\footnotetext{
${ }^{4}$ Em 1997, Adília Lopes publicou o livro $A$ bela acordada. Nele encontramos sete contos infantis, alguns dos quais resultam da reescritura de conhecidas histórias infantis, como: "Branca de neve e os sete anões", "A gata borralheira" e "A pequena sereia". Contudo, pelos títulos das histórias dado por Adília, podemos perceber o tom de ironia. São exemplos deles: "A casa dos anões outra vez", "Mais uma história da gata borralheira" ou "A sereia das pernas tortas".
} 
cuja mão tinha sido cortada por um malfeitor que queria roubar um anel. A solução da donzela, vendo o pastor "cheio de dor", foi "pregar" a mão encontrada no braço do pastor. Porém a sua ação foi insatisfatória, pois causou ainda mais dor no pastor.

Adília Lopes, em seu "poema-trança", faz um retrato às avessas dos contos de fadas. Predomina aqui a crueldade, ao mesmo tempo em que se relativizam a bondade e a maldade, geralmente confrontadas e questionadas nas versões mais conhecidas dessas histórias. O cenário fantasioso que encontramos nos contos de fadas é substituído por imagens "secas" que mais aterrorizariam as crianças, público a que se destinam estas histórias. Desde as primeiras "cenas" nos deparamos com imagens depreciativas e horrendas: a mão decepada encontrada pela donzela e a mão cortada do pastor.

Essa donzela, embora siga os moldes estereotipados, não passeia por jardins floridos ou castelos encantados, e sua bondosa ação se converte em dor e sofrimento. Graças à sua ingenuidade, ela julgou que a mão decepada que encontrara no caminho fosse a mesma mão do pastor arrancada pelo malfeitor. Diferentemente dos finais esperados nos contos de fadas, não há, neste poema, final feliz, muito menos justiça e reparação. $O$ malfeitor, antagonista da história, não sofre por sua conduta. Ele não é punido por ter decepado a mão do pastor para roubar um anel. Adília Lopes, nessa recriação poética, parece advertir para os sofrimentos que muitos padecem injustamente. Há inúmeros exemplos em que as ações danosas cometidas por uns, não são punidas, nem reparadas. Dessa forma, o único a sofrer duplamente aqui é o pastor: primeiramente pela ação criminosa do malfeitor e, depois, pela tentativa frustrada da donzela em restituir-lhe a mão.

O impasse dessa história foi ocasionado pelo irônico jogo de indefinição e definição dos artigos. Inicialmente, aproveitando e continuando a indefinição que encontramos nos contos infantis, a poetisa constrói as duas primeiras partes do poema (versos 1 ao 14) apenas usando artigos indefinidos: "uma vez" (verso 1), "uma donzela" (verso 2), "uma mão" (verso 4), "um pastor" (verso 8), "um malfeitor" (verso 10), "uma mão" (verso 12), "um anel" (verso 14); e nas outras duas partes (versos 15 ao 22) substitui a indefinição por artigos definidos: "A donzela" (verso 15), "a mão" (verso 16), "a dor" (verso 19).

Essa alternância instaura a dubiedade irônica do poema. O ato que a "bondosa" donzela procurou fazer, dando continuidade ao papel que seu personagem desempenha nos contos de fada, gera mais sofrimento no pastor. Pela maneira como é colocada, a donzela parece assumir, contrariamente, a figura de "antagonista" da história, pois sua ação contraria sua conduta. Ao invés de reparar o dano, ela apenas intensifica-o. 
Enfim, a reunião dos procedimentos estilísticos apontados por Adília Lopes, que serviram para identificar a concisão poética e a construção de uma "lírica mínima", pode ser sintetizada no poema metalinguístico abaixo:

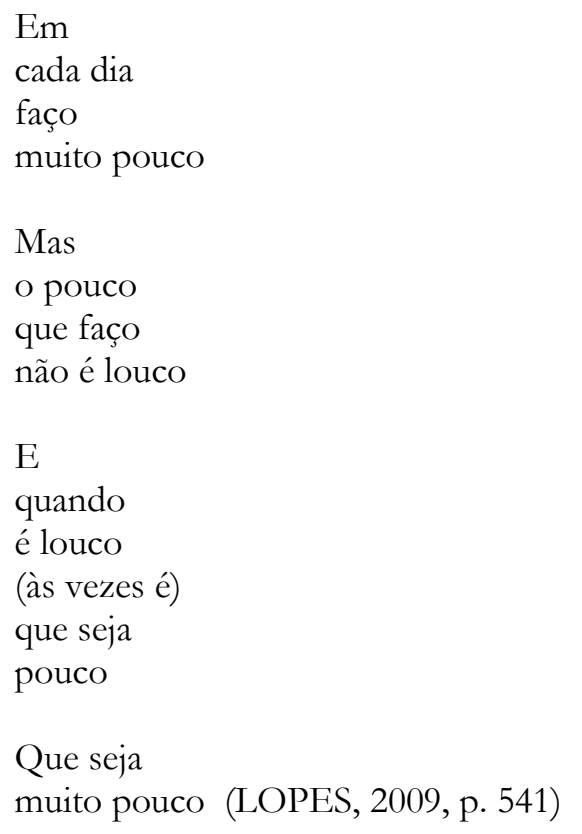

\section{BIBLIOGRAFIA}

LOPES, Adília. Apanhar ar. Lisboa: Assírio Alvim, 2010.

Dobra. Lisboa: Assírio Alvim, 2009.

MARTELO, Rosa Maria. "Contra a crueldade, a ironia". In: A forma informe. Lisboa: Assírio Alvim, 2010. 